\title{
Hydrodynamic factors affecting flux and fouling during ultrafiltration of skimmed milk
}

\author{
Alistair S. GRANDISON*, Wirote YourAVOnG, Michael J. LeWIS \\ Department of Food Science and Technology, The University of Reading, \\ Whiteknights, Reading RG6 6AP, UK
}

\begin{abstract}
The effects of independently varying both wall shear stress $\left(\tau_{w}\right)$ and transmembrane pressure $(T M P)$ on permeate flux and fouling during ultrafiltration of reconstituted skimmed milk in total recycle mode have been investigated. Irreversible fouling resistance $\left(R_{i f}\right)$ increased as TMP increased. Increasing $\tau_{w}$ at constant TMP led to an increase in both the initial flux, and subsequent flux decline, and to a decrease in $R_{i f}$. At the highest $\tau_{w}$, increasing TMP resulted in greater initial flux accompanied by increasing rates of flux decline and more irreversible fouling. Increasing and then decreasing TMP in a controlled, stepwise manner at constant $\tau_{w}$ suggested that flux is governed by both a reversible, and an irreversible fouling layer which forms at higher TMP; this also controlled the transmission of protein. Critical operating conditions producing the least fouling were evaluated during this procedure.
\end{abstract}

ultrafiltration / fouling / critical flux / wall shear stress

\section{INTRODUCTION}

The major problem of pressure-driven membrane processing is fouling, which results in flux decline and changing retention characteristics [12]. Fouling limits membrane performance, reduces the working life of membranes and increases cleaning costs [4].

Flux behaviour during ultrafiltration is determined by a number of factors including composition of the feed, membrane properties and hydrodynamic conditions. For example, with low protein feeds such as cheese whey, flux declines steadily with time due to irreversible adsorption of proteins and deposition of salts on the membrane, whereas with milk under the same operating conditions, the flux is initially lower but remains constant, probably being controlled by concentration polarisation [4, 14]. Also the flux patterns observed during

\footnotetext{
* Correspondence and reprints. agrandis@ afnovell.reading.ac.uk
} 
ultrafiltration of skimmed milk using tubular or hollow fibre membranes have been shown to be quite different to spiral-wound systems [5, 17]. These observations probably relate to differences in hydrodynamic conditions.

During ultrafiltration of skimmed milk, permeate flux can be improved by increasing the cross-flow velocity or the transmembrane pressure of the feed [4]. Increasing the cross-flow velocity and transmembrane pressure with spiral wound membranes leads to increased initial flux and changing flux pattern [5]. This suggests that flux and fouling are controlled by hydrodynamic factors.

However, limited information is available regarding the effect of hydrodynamic conditions on flux behaviour, fouling and retention characteristics during ultrafiltration of milk. Previous studies on permeate flux during ultrafiltration of milk have generally aimed to predict flux under steadystate conditions [5] where the membrane may already be fouled, while little work has attempted to investigate how fouling develops and the role of hydrodynamic factors in this development. This study aimed to determine the influence of TMP and $\tau_{w}$ on flux behaviour, fouling and transmission characteristics during ultrafiltration of reconstituted skimmed milk and to determine the role of these variables on the mechanisms of flux and fouling. In this way it was hoped to enable prediction of the operating conditions producing the least fouling using a critical flux concept $[3,7,20]$.

\section{MATERIALS AND METHODS}

\subsection{Membrane system and operation}

A tubular membrane was used (Paterson Candy International, Hants, UK). The membranes were composed of PVDF, MWCO $200000 \mathrm{~g} \cdot \mathrm{mol}^{-1}$, with internal diameter $1.25 \mathrm{~cm}$, active membrane length $57.6 \mathrm{~cm}$ providing membrane area $226 \mathrm{~cm}^{2}$. Pres- sure transducers (Ellision Sensors, Model GS4001, Wrexham, UK) were used to measure the pressure at the inlet $\left(P_{i}\right)$ and outlet $\left(P_{o}\right)$ of the membrane, and of the permeate (accuracy $\pm 1 \mathrm{kPa}$ ). The pressure transducers were positioned as close to the inlet and outlet of the membrane as physically possible. The permeate was collected and weighed (accuracy $\pm 0.1 \mathrm{~g}$ ) continuously to measure its flow rate. The temperature of feed was controlled by a heat exchanger. All of these parameters were measured every $30 \mathrm{~s}$ and monitored using a data logger system (Eltek,1000 Series, Chesterfield, UK). The cross-flow velocity was changed using a variable speed, $4.4 \mathrm{~kW}$ centrifugal pump (Puma, APV, Crawley, UK) with motor speed controller.

\subsection{Membrane performance}

By assuming that the osmotic pressure is very small the permeate flux $(J)$ can be expressed as:

$$
J=\frac{T M P}{\mu_{p}\left(R_{T}\right)}
$$

where $\mu_{p}$ is permeate viscosity, TMP is the transmembrane pressure which can be calculated by the following equation:

$$
T M P=\frac{P_{i}+P_{o}}{2}-P_{p}
$$

where $P_{i}$ and $P_{o}$ are inlet and outlet pressure respectively and $P_{p}$ is permeate pressure.

$R_{T}$ is the total hydraulic resistance, comprising the membrane resistance $\left(R_{m}\right)$ and the fouling resistance $\left(R_{f}\right)$ :

$$
R_{T}=R_{m}+R_{f} .
$$

$R_{m}$ reflects the physical properties of the membrane. $R_{m}$ for polymeric membranes was found to increase with increasing TMP and operating time due to membrane compaction [16]. $R_{m}$ for PVDF membrane in the range of TMP $0-3.5$ bar and time 0-90 min was determined experimentally during 
ultrafiltration of de-ionized water, thus obviating the effects of fouling and concentration polarisation.

$\mathrm{R}_{f}$ can be broken down to reversible fouling resistance $\left(R_{r f}\right)$ and irreversible fouling resistance $\left(\mathrm{R}_{i f}\right)$ :

$$
R_{f}=R_{r f}+R_{i f} .
$$

$\mathrm{R}_{\text {if }}$ was estimated after the membrane was fouled, by replacing the feed with water to eliminate reversible fouling resistance (see detail in experiment procedure). The water flux of the fouled membrane was then determined to estimate the irreversible fouling resistance by the following equation:

$$
R_{i f}=\frac{T M P}{\mu_{p} J_{w f}}-R_{m}
$$

where $J_{w f}$ is water permeate flux of the fouled membrane. $R_{r f}$ at the end of run was calculated by using equations (3) and (4).

$\tau_{w}$ represents the shear forces on the surface of the membrane and can be calculated by the following equation using experimental values of $P_{i}$ and $P_{o}$ [8]:

$$
\tau_{w}=\frac{d_{h}\left(P_{i}-P_{o}\right)}{4 L}
$$

where $d_{h}$ is the hydraulic diameter and $\mathrm{L}$ is the length of membrane.

Protein transmission $\left(T_{r}\right)$ was calculated according to the following equation:

$$
T_{r}=\frac{C_{p}}{C_{r}}
$$

where $C_{p}$ and $C_{r}$ are the concentrations of the protein in the permeate and the retentate respectively.

\subsection{Reconstituted skimmed milk}

Reconstituted skim milk (8.2\% total solids, $3.2 \%$ protein, pH 6.65-6.75) was prepared by adding medium heat skim milk powder to warm water in a jacketed vat with gentle agitation. It was thoroughly dissolved and then heated to $50{ }^{\circ} \mathrm{C}$ before processing.
The same batch of powdered milk was used in all experiments to ensure that changes in measured parameters did not result from variation in milk composition.

\subsection{Analytical methods}

Total solids and protein contents of milk samples were measured using a Dairylab2 (Multispec Ltd, York, UK).

Protein content of the permeate samples was measured using the Bradford Assay Kit (Sigma Diagnostics, London, UK).

Viscosities of permeate and milk samples were measured using an Ostwald U-tube (BS/U) capillary direct flow viscometer.

\subsection{Experimental procedures}

The effects of TMP and $\tau_{w}$ on flux, irreversible fouling and protein transmission were studied. Experiments were carried out in total recycle mode, at $50{ }^{\circ} \mathrm{C}$. Fifteen kilograms of reconstituted skim milk was used in each run. Note that this is equivalent to a volume reduction ratio of 1 . All experimental runs were carried out at least in duplicate.

The effect of varying $\operatorname{TMP}(0.5,1.5,2.5$ and 3.5 bar) was investigated at constant conditions of $\tau_{w}$ (19 and $227 \mathrm{~Pa}$ ). In a further series of experiments the effect of varying $\tau_{w}$ $(19,76,152$ and $227 \mathrm{~Pa})$ at constant TMP (3.5 bar) was studied.

For each set of processing conditions, the feed tank was first filled with soft water at $50{ }^{\circ} \mathrm{C}$ to warm up the system and evaluate the water flux. Then the water was replaced with reconstituted skimmed milk. The permeate valve was completely shut off before the chosen operating conditions were set, and then gradually opened until the appropriate $T M P$ was obtained. The permeate flux was monitored and recorded every $30 \mathrm{~s}$ by the logging system. After $60 \mathrm{~min}$ the milk was replaced and flushed with soft water at 
$50{ }^{\circ} \mathrm{C}$, at cross-flow velocity $2 \mathrm{~m} \cdot \mathrm{s}^{-1}$ for 2 min while the permeate flux was completely shut-off. The average water flux was evaluated at TMP 0.5 bar and $50{ }^{\circ} \mathrm{C}$ over a period of 3 min to calculate $\mathrm{R}_{i f}$. A permeate sample was collected for $3 \mathrm{~min}$ up to the specified time, for evaluation of protein transmission.

A further series of experiments was carried out in which the permeate flux was monitored during stepwise increasing and decreasing of TMP at constant $\tau_{w}(227 \mathrm{~Pa})$. Each TMP level was maintained for $20 \mathrm{~min}$, except for at the highest level of TMP where conditions were maintained for $40 \mathrm{~min}$. A sample of permeate was collected over the final $3 \mathrm{~min}$ at each TMP stage, for evaluation of protein transmission.

\section{RESULTS AND DISCUSSION}

\subsection{The influence of TMP and $\tau_{w}$ on flux decline, irreversible fouling and protein transmission}

The experimental error in all investigated parameters was determined by calculating standard deviation (SD), which indicated very good reproducibility. The limits of percentage errors were as follows: $\tau_{w}$ (SD < $7 \%), T M P(<5 \%), J(<5 \%), R_{i f}(<12 \%)$ and $T_{r}(<2 \%)$.

\subsubsection{The effect of TMP at low $\tau_{w}(19 \mathrm{~Pa})$}

The fluxes at each value of TMP were almost constant with time during 1 hour's processing (Fig. 1a). There was a small increase in flux with increasing TMP over a seven-fold range (from $17 \pm 0.5 \mathrm{~kg} \cdot \mathrm{m}^{-2} \cdot \mathrm{h}^{-1}$ at 0.5 bar to $20 \pm 1 \mathrm{~kg} \cdot \mathrm{m}^{-2} \cdot \mathrm{h}^{-1}$ at $3.5 \mathrm{bar}$ ). Under these conditions, the irreversible fouling resistance (at the end of run) was small $\left(1.77 \pm 0.11 \times 10^{12} \mathrm{~m}^{-1}\right.$ at 0.5 bar to $2.82 \pm$ $0.29 \times 10^{12} \mathrm{~m}^{-1}$ at 3.5 bar) compared to the reversible fouling resistance (at the end of run) $\left(10.7 \times 10^{12} \mathrm{~m}^{-1}\right.$ at 0.5 bar to $74.9 \times$
$10^{12} \mathrm{~m}^{-1}$ at 3.5 bar). This result suggests that the flux was almost pressure-independent, controlled by reversible fouling resistance [4]. Total hydraulic resistance at each $T M P$ did not change with time but increased greatly with increasing TMP. The contribution to reversible fouling resistance of concentration polarisation probably did not change with time because it would have been established in the first few seconds of processing, the rejected solute starting to form a polarisation layer instantaneously $[6,18]$. The irreversible fouling due to consolidation may have increased with processing time, especially at high $T M P$, but the resulting resistance would be small compared to the total hydraulic resistance. Both reversible and irreversible fouling increased significantly with increasing TMP (Fig. 2a). Irreversible fouling results from direct adsorption of soluble milk proteins onto the membrane surface, as well as deposition of milk proteins and salts during processing $[4,19]$. It is possible that an increase in $T M P$ encouraged the formation of irreversible fouling due to an increase in the amount of protein transported to the membrane surface by convection (permeate flux increase about 17\%) [2]. It has been reported that the deposit formed under high pressure is tight and difficult to remove $[10,15]$. The protein transmission at the end of run (60 min) of each condition is also presented in Figure 1a. Protein transmission decreased significantly with increased TMP. This could be due to an increase in both irreversible and reversible fouling [1].

\subsubsection{The effect of $\tau_{w}$}

Increasing $\tau_{w}$ up to $227 \mathrm{~Pa}$ at constant $T M P$ (3.5 bar) led to a large increase in the initial flux (0 min) and subsequent rate of flux decline (Fig. 1b). The initial flux at $\tau_{w}$ $227 \mathrm{~Pa}\left(154 \pm 2 \mathrm{~kg} \cdot \mathrm{m}^{-2} \cdot \mathrm{h}^{-1}\right)$ being approximately eight times greater than at $19 \mathrm{~Pa}$ $\left(20 \pm 1 \mathrm{~kg} \cdot \mathrm{m}^{-2} \cdot \mathrm{h}^{-1}\right)$. The increase in initial flux with increasing $\tau_{\mathrm{w}}$ was possibly due to an increase in the rate of particle (e.g. casein 
Figure 1. The effect of $T M P$ and $\tau_{w}$ on permeate flux and protein transmission during ultrafiltration of reconstituted skimmed milk $8.2 \%$ total solid, (a) at constant $\tau_{w}$ (19 Pa, open symbol, 227 Pa: closed symbol), (b) at constant $T M P$ (3.5 bar).
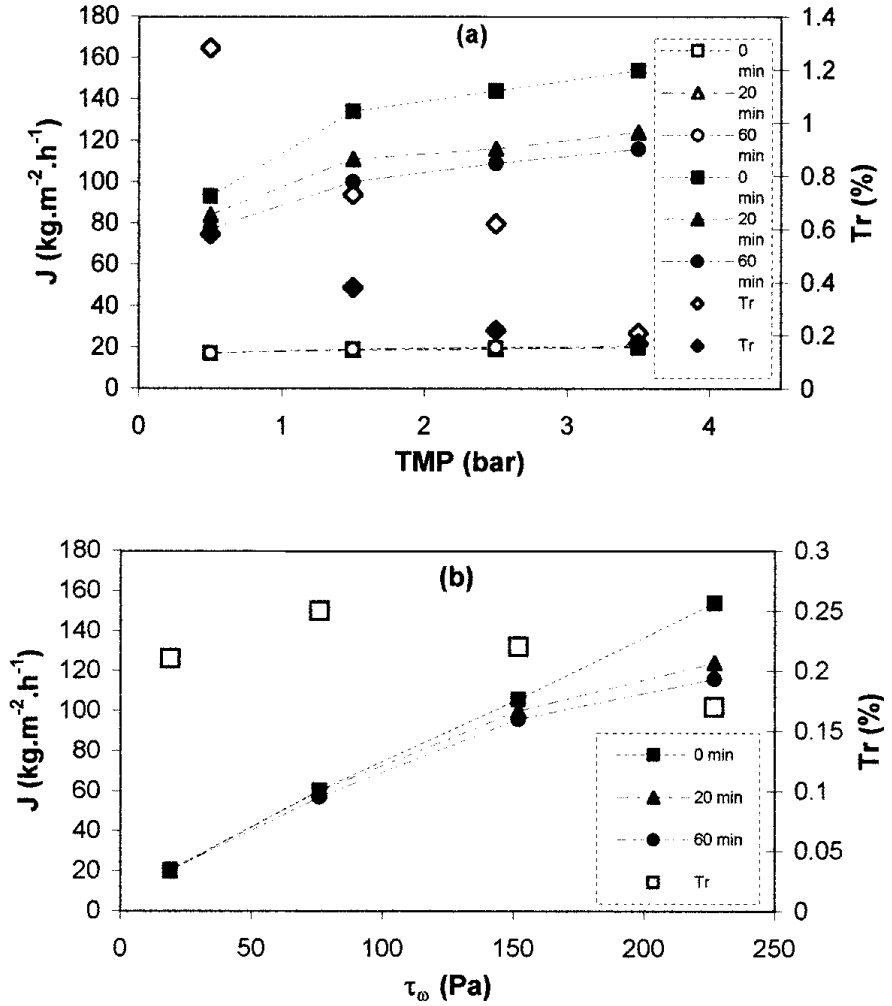

micelles, whey proteins or insoluble matter) removal, which could result from an increase in back diffusion and shear enhanced diffusion [3]. In addition, the rate of flux decline increased with increasing $\tau_{w}$ which may be due to an increased rate of particle deposition resulting from the increased initial flux, the rate of particle deposition being higher than the rate of particle removal. As $\tau_{w}$ increased, the reversible fouling resistance was decreased greatly (from $74.9 \times 10^{12} \mathrm{~m}^{-1}$, at $\tau_{w}=19 \mathrm{~Pa}$ to 9.6 $\times 10^{12} \mathrm{~m}^{-1}$, at $\tau_{w}=227 \mathrm{~Pa}$ ) while irreversible fouling decreased significantly from $2.82 \pm 0.29 \times 10^{12} \mathrm{~m}^{-1}(\tau, 19 \mathrm{~Pa})$ to $1.70 \pm$ $0.13 \times 10^{12} \mathrm{~m}^{-1}\left(\tau_{w}=227 \mathrm{~Pa}\right)$ (Fig. 2b). This result suggests that $\tau_{w}$ has a role in removal of particles away from the membrane surface by erosion. Moreover, protein transmission decreased with increased $\tau_{w}$ (Fig. 1b) which was unexpected as both the irre- versible and reversible fouling decreased. One explanation could be that the irreversible fouling layer at high $\tau_{w}$ (and therefore high flux) was less porous, or became more localised at the pore entrance, thus reducing effective pore size $[10,13]$. The shear force may remove the larger casein micelles, whereas smaller particles (e.g. whey proteins, small micelles) would remain on the surface of the membrane and be responsible for build up of fouling [11] and/or filling in gaps in the porous cake layer, reducing its porosity [14].

\subsubsection{The effect of TMP at high $\tau_{w}$ (227 Pa)}

The influence of TMP at the highest $\tau_{w}$ $(227 \mathrm{~Pa})$ is shown in Figure 1a. Unlike at lower $\tau_{w}(19 \mathrm{~Pa})$ the flux at all TMP levels declined with time. Increasing the TMP 

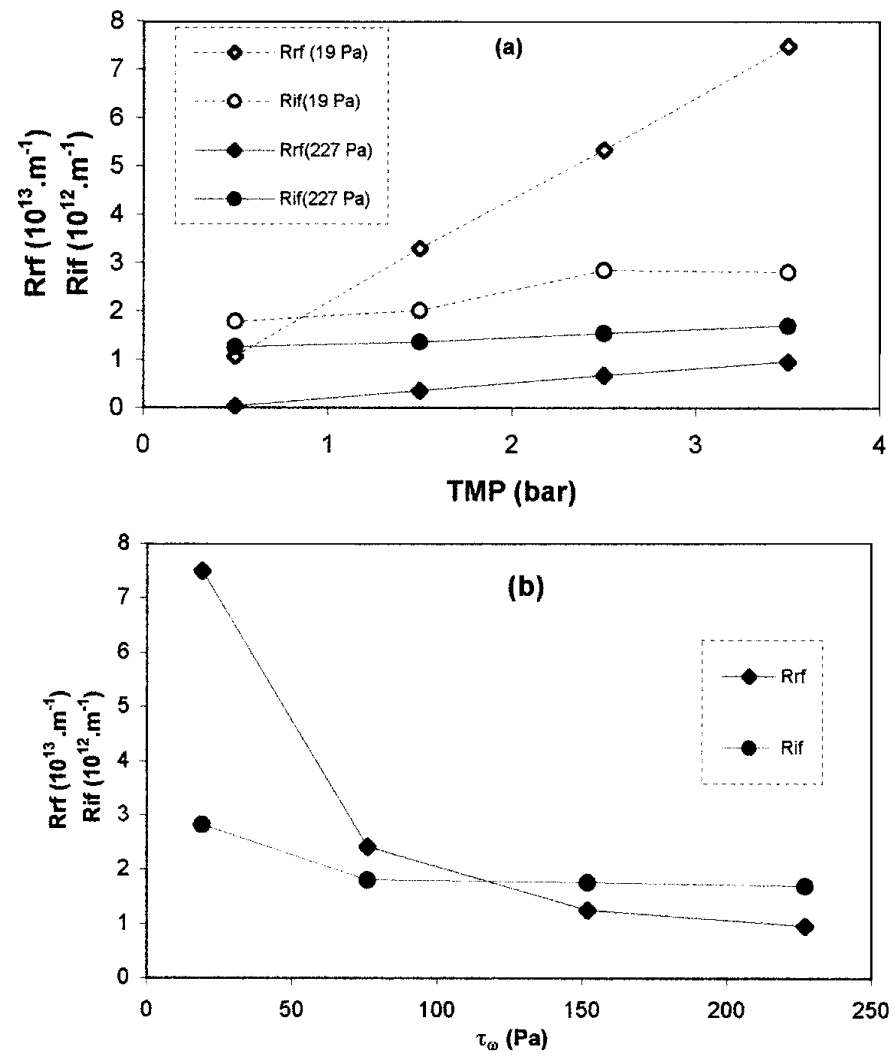

Figure 2. The effect of $T M P$ and $\tau_{w}$ on reversible fouling resistance $\left(R_{r f}\right)$ and irreversible fouling resistance $\left(R_{i f}\right),(\mathbf{a})$ at constant $\tau_{w}$ (19 and $227 \mathrm{~Pa}),(\mathbf{b})$ at constant TMP (3.5 bar).

resulted in increases in both the initial flux and the rate of flux decline, suggesting that the flux was in the pressure-dependent region. However, the effect of increasing $T M P$ from 0.5 bar (initial flux $=93 \pm$ $2 \mathrm{~kg} \cdot \mathrm{m}^{-2} \cdot \mathrm{h}^{-1}$ ) to $1.5 \mathrm{bar}$ (initial flux $=134 \pm$ $3 \mathrm{~kg} \cdot \mathrm{m}^{-2} \cdot \mathrm{h}^{-1}$ ) was much greater than subsequent increases to 2.5 bar (initial flux $=$ $144 \pm 3 \mathrm{~kg} \cdot \mathrm{m}^{-2} \cdot \mathrm{h}^{-1}$ ) and $3.5 \mathrm{bar}$ (initial flux $\left.=154 \pm 2 \mathrm{~kg} \cdot \mathrm{m}^{-2} \cdot \mathrm{h}^{-1}\right)$. This could be due to a higher resistance due to reversible fouling at the higher values of TMP (Fig. 2a), in which the flux approached the limiting flux. The rate of flux decline increased as TMP (or flux) increased. This result indicates that permeate flux plays an important role in particle deposition causing the flux decline. Increasing TMP led to increased irreversible fouling (Fig. 2a). This was pos- sibly due to more solute deposition on the membrane surface by convective transport (permeate flux) followed by consolidation at high TMP to form a stronger deposit which could not be removed by the force of erosion. Furthermore, protein transmission also decreased as TMP (or flux) increased (Fig. 1a) which suggests that the fouling developed at high $\tau_{w}$ was caused by smaller particles resulting in a less porous deposit. However, the increase in reversible fouling as TMP increased may also have contributed to the reduction.

The significant effects of both TMP and $\tau_{\mathrm{w}}$ on the ultrafiltration performance, including flux, fouling and protein transmission suggest that under conditions where irreversible fouling is reduced (i.e. high wall shear stress), fouling could be minimised 


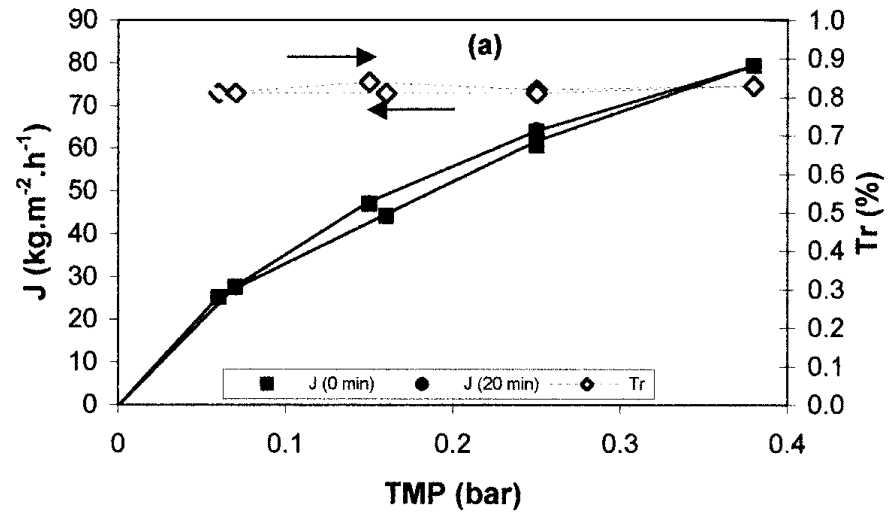

Figure 3. Flux behaviour and protein transmission during ultrafiltration of reconstituted skimmed milk at constant $\tau_{w}(227 \mathrm{~Pa})$ with stepwise increasing and decreasing $T M P,(\mathbf{a})$ maximum TMP 0.38 bar, (b) maximum TMP 3.5 bar.

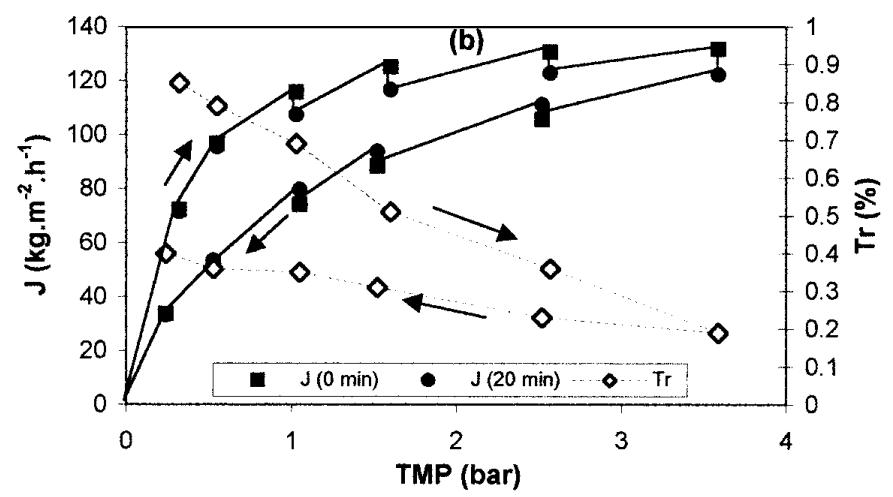

and constant flux could be maintained by balancing the particle erosion rate (using shear force) and particle deposition (controlled by permeate flux) as also suggested by Gesan et al. [9].

\subsection{Critical operating conditions}

\subsubsection{Flux behaviour and fouling characteristics}

The response of permeate flux during stepwise increasing and decreasing TMP at constant, high $\tau_{w}(227 \mathrm{~Pa})$, was investigated over two ranges of TMP (0-0.38 bar and 0.32-3.59 bar). For the higher TMP range (Fig. 3b), the flux increased with each step increase in $T M P$. Initial flux and flux after running for $20 \mathrm{~min}$ (40 min at 3.59 bar) are shown for each TMP level. The difference between the initial flux and the flux at $20 \mathrm{~min}$ at the lower TMP levels ( 0.32 and 0.55 bar) was very small. As TMP was increased to 1 bar the flux decreased from 116 initially to $107 \mathrm{~kg} \cdot \mathrm{m}^{-2} \cdot \mathrm{h}^{-1}$ after $20 \mathrm{~min}$ and similar flux decline with time was observed at the higher TMP values. However, the flux did not increase greatly as TMP increased from 2.5 to 3.59 bar indicating that the flux was approaching the limiting flux, which was about $120 \mathrm{~kg} \cdot \mathrm{m}^{-2} \cdot \mathrm{h}^{-1}$. The flux decline with time may have been due to increasing permeate flux leading to increased particle deposition rates which were higher than particle removal rates [9].

With stepwise decreases in TMP, it was also notable that the reduction in flux with each step was followed by an increase in 
the permeate flux with time. This may have been due to reduced particle deposition rates resulting from decreased permeate flux, the particle removal rates becoming higher than the particle deposition rates. This suggests that the deposit, which had formed as TMP increased, could be removed by the wall shear force. Moreover, the flux during the decreasing TMP steps was considerably lower than that during the increasing steps at the same TMP levels. Thus hysteresis was observed. This suggests that an irreversible deposit also formed, which could not be removed by the wall shear force.

When a similar exercise was carried out at lower TMP levels (0-0.38 bar) (Fig. 3a), the flux increased or decreased with stepwise changes in TMP, as before, but subsequently remained constant with time in all cases. This indicates that a balance between particle removal rate and particle deposition rate existed under these conditions. The fluxes during the decreasing steps were also lower than during increasing TMP, but the differences were less marked than over the high TMP range. Therefore, only a very small hysteresis was observed. This result suggests that less irreversible fouling occurred at lower TMP.

Protein transmission was also investigated during the stepwise increasing and decreasing of TMP. Under the conditions of high TMP and flux (Fig. 3b), transmitted protein decreased as TMP and flux increased, but subsequently recovered partially as $T M P$ decreased, suggesting that both reversible and irreversible fouling affected the protein transmission. On the other hand, protein transmission remained constant $\left(T_{r}(\%)=0.82\right)$ over the lower range of TMP (Fig. 3a). Presumably changes in irreversible or reversible fouling were not sufficient to affect protein transmission in the latter case. However, the protein transmission was considerably higher compared to levels usually found in the dairy industry [4] where protein transmission is about $0.1 \%$. This was probably because the mem- brane used in this study had a bigger pore size $\left(200000 \mathrm{~g} \cdot \mathrm{mol}^{-1}\right)$ compared to those normally used for ultrafiltration in the dairy industry (around $25000 \mathrm{~g} \cdot \mathrm{mol}^{-1}$ ). It is also possible that under these conditions both reversible and irreversible fouling was low.

\subsubsection{Critical flux concept}

The critical flux concept for membrane filtration has been proposed by Field et al. [7]. Critical flux can be considered to be the flux just below that at which deposition onto the membrane to form a cake layer begins. At this point a concentration polarisation layer is present, but this does not become solidified into a cake on the membrane surface and in principle is reversible. They claimed that operating membrane filtration at a permeate flux lower than or equal to the critical flux could reduce or eliminate irreversible membrane fouling. Critical flux is determined by hydrodynamic conditions, pore size and composition of the feed, and is sometimes equal to limiting flux but in other cases operating membrane filtration at the limiting flux causes more fouling. The critical flux can be evaluated by investigating $T M P$ at controlled permeate flux levels. Increasing TMP at a given flux indicates that the balance of particle convection and removal has shifted towards deposition, and hence the critical flux has been exceeded [3]. At fluxes equal to or lower than the critical flux, the relationship between TMP and flux should be linear with no hysteresis [20]. Two forms of the critical flux have been proposed [20]. The "strong" form of critical flux exists if the flux of a suspension is identical to the flux of clean water at the same $T M P$. The "weak" form of critical flux exists if the relationship between flux and TMP is linear, but the slope of the line differs from that for clean water. The latter case only would be relevant to the current study.

The value of the critical flux will also be influenced by $\tau_{w}$. The ratio of $J / \tau_{w}$ has been used to evaluate membrane filtration performance regarding fouling and selectivity. 
The ratio defines the balance of particle deposition rate (relating to $J$ ) and particle removal rate (relating to $\tau_{w}$ ) [9]. Operating conditions are recommended in which $J / \tau_{w}$ is lower than the critical value. This concept is similar to critical flux concept but also takes into account the effect of $\tau_{w}$.

The results from stepwise increasing and decreasing TMP enable the evaluation of the critical operating conditions required to minimise both reversible and irreversible fouling, using the critical flux concept. Chen et al. [3] observed a small hysteresis effect even at fluxes below the critical flux in similar experiments using colloidal silica suspensions. Since only a small hysteresis was observed in Figure 3a, and the relationship between flux and TMP was almost linear, the flux obtained was probably lower than the weak form of the critical flux at all pressures. However, the change in flux characteristics occurring at TMP of 1 bar, as observed in Figure $3 \mathrm{~b}$, suggest that at high $\tau_{w}(227 \mathrm{~Pa})$ the critical flux would be around $90-100 \mathrm{~kg} \cdot \mathrm{m}^{-2} \cdot \mathrm{h}^{-1}$. This would result in a ratio of $\mathrm{J} / \tau_{w}$ of approximately $0.4 \mathrm{~kg} \cdot \mathrm{m}^{-2}$. $\mathrm{h}^{-1} \cdot \mathrm{Pa}^{-1}$. Gesan et al. [9] carried out microfiltration of skimmed milk using a $0.1 \mu \mathrm{m}$ pore size tubular ceramic membrane at constant volume reduction ratio of 2 . Their data produced a ratio of $J / \tau_{w}$ of approximately $0.6 \mathrm{~kg} \cdot \mathrm{m}^{-2} \cdot \mathrm{h}^{-1} \cdot \mathrm{Pa}^{-1}\left(\tau_{w}^{w}=100 \mathrm{~Pa}\right.$, critical flux $=58 \mathrm{~kg} \cdot \mathrm{m}^{-2} \cdot \mathrm{h}^{-1}$ ) which is comparable to the current study. Differences would be expected due to the different pore size, membrane material and feed composition.

\section{CONCLUSION}

The hydrodynamic factors, TMP, permeate flux and $\tau_{w}$ played an important role in flux pattern and fouling characteristics. Increasing TMP increased both reversible and irreversible fouling. Increasing $\tau_{w}$ led to increased permeate flux as well as reducing the reversible and irreversible fouling due to an increase in particle removal rate.
The permeate flux played an important role in particle deposition rate, influencing both reversible and irreversible fouling. Both reversible and irreversible fouling affected the transmission of protein. Low irreversible fouling and constant flux were obtained when flux was lower than the critical flux. The critical flux at $\tau_{w}=227 \mathrm{~Pa}$ was about 90-100 kg. $\mathrm{m}^{-2} \cdot \mathrm{h}^{-1}$.

Current studies aim to discover the effect of wall shear stress, concentration, the physico-chemical properties of the milk as well as the influence of membrane characteristics on the critical flux. This should help to ensure more efficient ultrafiltration of milk.

\section{ACKNOWLEGEDGEMENTS}

The authors would like to thank the Royal Thai Government for providing sponsorship for Mr Youravong.

\section{REFERENCES}

[1] Altmann J., Ripperger S., Particle deposition and layer formation at the crossflow microfiltration, J. Membrane Sci. 124 (1997) 119-128.

[2] Brauser H., Chmiel H., Stroh N., Walitza E., Control of concentration polarization and fouling of membrane in medical and biomedical application, J. Membrane Sci. 27 (1986) 195-202.

[3] Chen V., Fane A.G., Madaeni S., Wenten I.G., Particle deposition during membrane filtration of colloids: transition between concentration polarisation and cake formation, J. Membrane Sci. 125 (1997) 109-122.

[4] Cheryan M., Ultrafiltration and microfiltration hand book, 2nd ed., Technomic Publishing Co, Lancaster, USA, 1997.

[5] Cheryan M., Chiang B.H., Performance and fouling behavior of hollow fiber and spiral wound ultrafiltration module processing milk, Eng. Food 1 (1984) 191-197.

[6] Chudacek M.W., Fane A.G., The dynamics of polarisation in unstirred and stirred ultrafiltration, J. Membrane Sci. 21 (1984) 145-160.

[7] Field R.W., Wu D., Howell J.A., Critical flux concept for microfiltration fouling, J. Membrane Sci. 100 (1995) 259-272. 
[8] Gerhart E.M., Gross R.J., Hocutein J.I., Steady incompressible flow in pipes and ducts, in: Fundamental of Fluid mechanics, 2nd ed., Addison-Wesley Publishing Company, USA, 1993, pp. 462-582.

[9] Gesan G., Boyaval E., Daufin G., Critical operating conditions during cross flow microfiltration of skim milk, in: Fouling and Cleaning in Food Processing, Conference Proceedings, Jesus College, Cambridge, UK, 1998.

[10] Kim K.J., Fane A.G., Fell C.J.D., Joy D.C., Fouling mechanisms of membranes during protein ultrafiltration, J. Membrane Sci. 68 (1992) 79-91.

[11] Le Berre O., Daufin G., Skimmilk crossflow microfiltration performance versus permeate flux to wall shear stress ratio, J. Membrane Sci. 117 (1996) 261-270.

[12] Marshall A.D., Munro P.A., Tragardh G., The effect of protein fouling in microfiltration and ultrafiltration on permeate flux, protein retention and selectivity: A literature review, Desalination 91 (1993) 65-108.

[13] Marshall A.D., Munro. P.A., Tragardh G., Influence of flux on fouling during the microfiltration of $\beta$-lactoglobulin solution under cross flow conditions, J. Membrane Sci. 130 (1997) 23-30.
[14] Merin U., Cheryan M., Factors effecting the mechanism of flux decline during ultrafiltration of cottage cheese whey, J. Food Process Preserv. 4 (1980) 183-198.

[15] Nakanishi K., Kessler H.G., Rinsing behaviour of deposited layers formed on membranes in ultrafiltration, J. Food Sci. 50 (1985) 1726-1731.

[16] Persson K.M., Gekas V., Tragardh G., Study of membrane compaction and its influence on ultrafiltration water permeability, J. Membrane Sci. 76 (1995) 155-162.

[17] Ramachandra Rao H.G., Grandison A.S., Lewis M.J., Flux pattern and fouling of membranes during ultrafiltration of some dairy products, J. Sci. Food Agric. 66 (1994) 563-571.

[18] van Oers C.W., Vorstman M.A.G., Muijselaar W.G.H.M., Kerkhof P.J.A.M., Unsteady-state flux behaviour in relation to the presence of gel layer, J. Membrane Sci. 73 (1992) 231-246.

[19] Vetier C., Bennarsar M., Tarodo de la Fuente B., Study of the fouling of a mineral microfiltration membrane using scanning electron microscopy and physicochemical analysis in processing of milk, J. Dairy Res. 55 (1998) 381-400.

[20] Wu D., Howell J.A., Field R.W., Critical measurement for model colloids, J. Membrane Sci. 152 (1999) 89-98. 